
Military Technical College
Kobry El-Kobbah,
Cairo, Egypt.

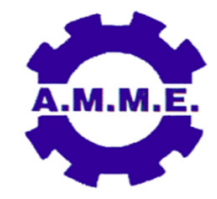

\title{
CONTROL STRATEGY DEVELOPMENT FOR INDEPENDENT WHEEL TORQUE DISTRIBUTION FOR MULTI-WHEELED COMBAT VEHICLE
}

\author{
H. Ragheb*, M. El-Gindy** and H. A. Kishawy***
}

\begin{abstract}
Multi-wheeled combat vehicles behavior depends not only on the available total driving torque but also on its distribution among the drive axles/wheels. In turn, this distribution is largely regulated by the drivetrain layout and its torque distribution devices.

In this paper, a multi-wheeled (8x4) combat vehicle bicycle model has been developed and used to obtain the desired yaw rate and lateral acceleration to become reference for the design of the controllers. PID controllers were designed as upper and lower layers of the controllers. The upper controller develops the corrective yaw moment, which is the input to the lower controller to manage the independent torque distribution (torque vectoring) among the driving wheels. Several simulation maneuvers have been performed at different vehicle speeds using Matlab/ Simulink-TruckSim to investigate the proposed torque vectoring control strategy. The simulation results with the proposed controller showed a significant improvement over conventional driveline, especially at severe maneuvers.
\end{abstract}

\section{KEY WORDS}

Multi-wheeled vehicle, vehicle model, TruckSim, validation, handling characteristics, Simulink, 8x4 combat vehicle, control strategy, PID controller.

\section{NOMENCLATURE}

\begin{tabular}{|c|l|c|l|}
\hline Symbol & \multicolumn{1}{|c|}{ Description } & Symbol & \multicolumn{1}{|c|}{ Description } \\
\hline$\delta$ & Wheel steering angle. & $\mathrm{u}$ & Vehicle longitudinal speed. \\
\hline$\alpha$ & Tire slip angle. & $\mathrm{V}$ & Vehicle Lateral speed. \\
\hline $\mathrm{r}$ & Yaw rate. & $\beta$ & Vehicle sideslip angle. \\
\hline $\mathrm{a}_{\mathrm{y}}$ & Lateral Acceleration. & $\mathrm{C}_{\alpha}$ & Tire cornering stiffness. \\
\hline
\end{tabular}

\footnotetext{
* $\quad$ Graduate Student, University of Ontario Institute of Technology (UOIT).

** Professor of Automotive Engineering, University of Ontario Institute of Technology (UOIT).

*** Professor and Associate Dean, University of Ontario Institute of Technology (UOIT).
} 


\section{INTRODUCTION}

Since the 1980s, many vehicle dynamics control technologies have been proposed. Direct yaw moment control with brakes was an active technology for preventing accidents and become commonly used today. Kaoru Sawase [1] developed the world's first vehicle with a right-and-left torque vectoring direct yaw moment control system. The developed control system directly controls the yaw moment acting on the vehicle regardless of vehicle accelerating or decelerating status by distributing the available driving torque between the left and right wheels.

Mohan and Weals [2,3] proposed different torque vectoring systems. There have been many reports on improved performance of vehicle dynamics on AWD and RWD vehicles using torque-vectoring technology.

Kaoru Sawase et al. [4] developed the Super All Wheel Control (S-AWC) system that excellently enhance the ability of all four tires in a balanced way to realize predictable handling and high performance. A direct yaw moment control technology that effects left-right torque vectoring, which forms the core of S-AWC system, can control cornering maneuvers as desired during acceleration, steady state driving, and deceleration.

In addition, Damrongrit Piyabongkarn et al. [5] developed a yaw control approach using the biasing devices; the driveline system was established on nominal front wheel- drive operation with on-demand transfer of torque to the rear. The torque biasing components of the system were an electronically controlled center coupler and a rear electronically controlled limited slip differential. Simulation results showed the effectiveness of the torque biasing system in achieving yaw stability control.

Shuibo Zheng [6] developed a Vehicle Dynamics Control (VDC) system for tracking desired vehicle behavior for vehicle stability enhancement. The proposed control system showed high robustness with respect to the change of road surface condition and various severe driving conditions such as $\mathrm{J}$-turn and lane change maneuvers.

Kaoru Sawase and Yuichi Ushiroda [7] investigated the equations representing the functions of the right-and-left torque vectoring system and its applicability to nondriving wheels. This study showed that it is most effective when applied to the front wheels on FWD vehicles and to the rear wheels on RWD and AWD vehicles.

Gerd Kaiser et al. [8] developed a new torque vectoring control strategy for an electric vehicle with two independent electric machines at the front wheels, which can be used as a base torque vectoring controller concept, which can be implemented in a real vehicle.

M. M. Al Emran Hasan et al. [9] investigated different torque based strategies to find a suitable and effective differential torque based ESC. Simulation results showed a promising possibility of using differential torque based ESC in an in-wheel EV.

In addition, H.Ragheb et al. [10] studied torque management devices starting from the conventional mechanical torque distribution devices, Active torque distribution systems (ATD) utilize active differentials to control the drive torque independently distributed to each driving wheel and accordingly provide active control of traction 
and yaw moment. This study showed that torque vectoring technology should be utilized for multi-wheeled vehicles in off-road operation especially on soft soil to enhance vehicle mobility performance.

Russell p. Osborn and Taehyun Shim [11] performed a sensitivity analysis using a simplified non-linear vehicle model to build up the basis for a successful vehicle dynamics control strategy.

In the literature, many other researches have examined various control methods to improve the maneuverability and stability of $4 \times 4$ vehicle configurations. Jackson and Crolla [12] proposed the yaw rate control method using direct yaw moment control to improve the stability of a six-wheeled vehicle. On the other hand, there has not been considerable research effort to develop maneuvering control algorithm for eightwheeled vehicles. Among the few publications of the $8 \times 8$ vehicle configuration, Wongun Kim et.al [13] proposed a drive control algorithm for an 8WD/4WS vehicle to enhance vehicle stability and maneuverability. It has been shown that the vehicle maneuverability has been improved by the proposed drive controller compared to simple drive controller.

In this paper, a validated full nonlinear combat vehicle model, H.Ragheb et al. [14], has been used to develop a torque vectoring controller using Matlab-Simulink to actively distribute the available driving torque among each of the driving wheels of the $8 \times 4$ combat vehicle configurations under investigation.

\section{VEHICLE MODEL}

Figure 1 shows the multi-wheeled combat vehicle model used in this study. The vehicle is equipped with four axles, which can be operated in either 4WD or 8WD, and independent suspensions. The vehicle model consists of 22 Degrees of freedom, namely pitch, yaw, roll and translational velocities in $X, Y$, and $Z$ directions of the vehicle sprung mass and spin and vertical motions of each wheel of the eight wheels.

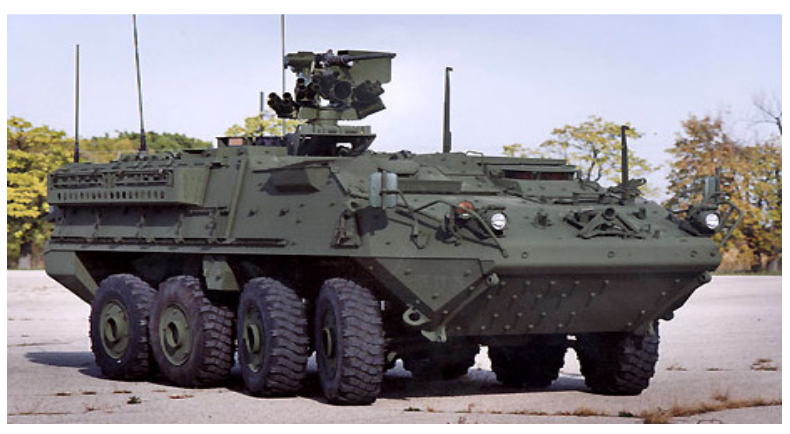

(a)

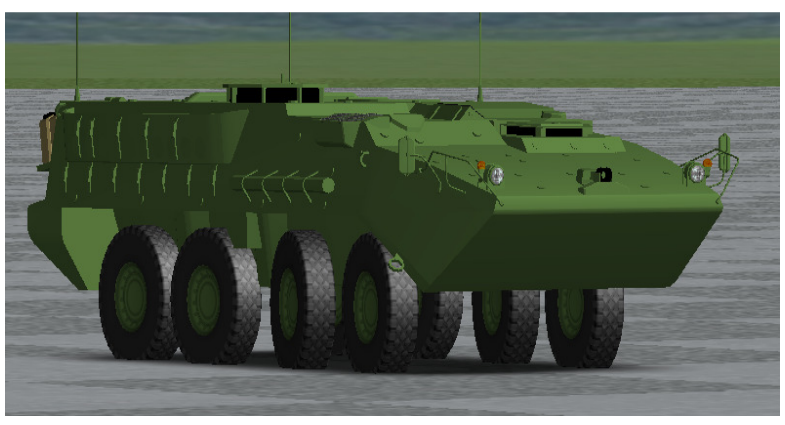

(b)

Fig. 1. (a) typical vehicle configuration (b) and the simulation model.

In this model the non-linear tire look-up tables of measured tire data obtained from tire manufacturer, Ragheb, $H$. et al. [14]. The model was validated against 
measurements performed at different speeds and maneuvers. The test results were provided in a technical report, El-Gindy, et al. [15].

\section{CONTROL STRATEGY}

In practice, the actual vehicle responses can be obtained from the measurements and appropriate conversions from various mounted sensors like wheel speed sensors, yaw rate sensor, steering angle sensor, lateral accelerometers, and online estimators, if any.

Ghoneim et al. [16] stated that the driver proposed responses like steering input, torque and braking inputs can be used to estimate desired (target) vehicle responses based on a linearized and simplified model of the vehicle. In the simulation study of this research, the desired responses are obtained from a bicycle model of the vehicle, Fig. 2. The vehicle states considered in this research are the yaw rate, lateral acceleration of the vehicle. The torque vectoring control strategy objective is to minimize the driver-required action in difficult situations. Based on this requirement, the driver has been excluded from all analysis of the proposed control strategy in this research.

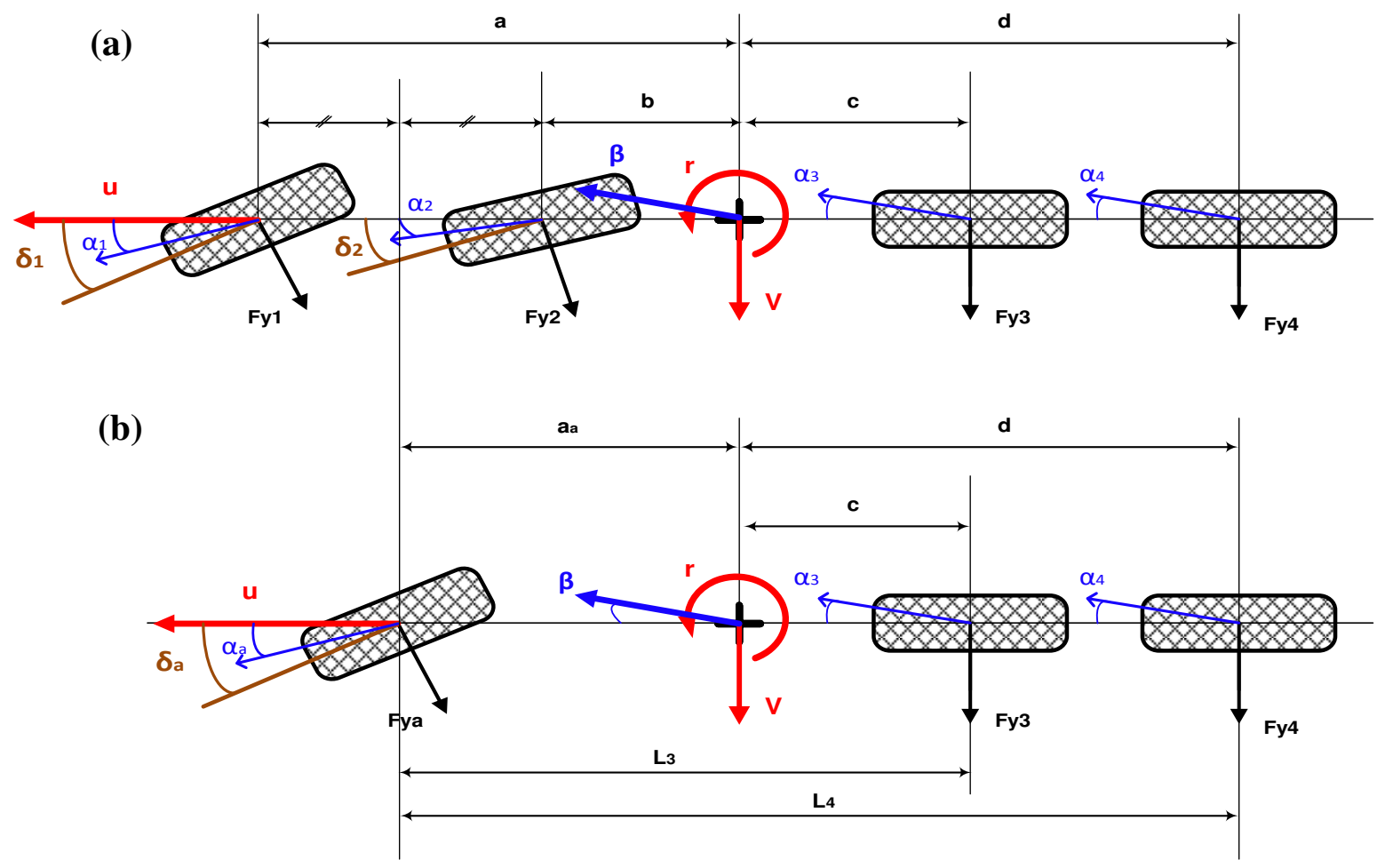

Fig. 2. (a) 4-Axle vehicle bicycle model and (b) bicycle model with combined front axles.

In most cases, the desired responses of the state variables are chosen from steady state values of the bicycle model. For a given road wheel steering angle the desired states are defined and can be extracted from the state space model.

For simplification $\left(\delta_{\mathrm{a}}, \alpha_{\mathrm{a}}\right)$ will be used to present the average steering input and slip angle of the combined first and second axle as follows: 


$$
\begin{gathered}
\delta_{a}=\frac{\delta_{1}+\delta_{2}}{2} \\
\alpha_{a}=\frac{\alpha_{1}+\alpha_{2}}{2} \\
\alpha_{a}=\delta_{a}-\left[\frac{V+a_{a} r}{u}\right]
\end{gathered}
$$

The slip angle of the third axle:

$$
\alpha_{3}=-\left[\frac{V-c r}{u}\right]
$$

The slip angle of the fourth axle:

$$
\alpha_{4}=-\left[\frac{V-d r}{u}\right]
$$

Steady state lateral velocity and yaw rate response to the average seeing input, respectively, are given from the following equations (4 and 5).:

$$
\begin{gathered}
{\left[V / \delta_{a}\right]_{s s}=\frac{u\left[L_{4} d C_{\alpha_{4}} C_{\alpha_{a}}+L_{3} c C_{\alpha_{3}} C_{\alpha_{a}}-m u^{2} a_{a} C_{\alpha_{a}}\right]}{L_{4}^{2} C_{\alpha_{a}} C_{\alpha_{4}}+L_{3}^{2} C_{\alpha_{a}} C_{\alpha_{3}}+C_{\alpha_{3}} C_{\alpha_{4}}(d-c)^{2}+m u^{2}\left(c C_{\alpha_{3}}+d C_{\alpha_{4}}-a_{a} C_{\alpha_{a}}\right)}} \\
{\left[r / \delta_{a}\right]_{s S}=\frac{u\left[L_{4} C_{\alpha_{4}} C_{\alpha_{a}}+L_{3} C_{\alpha_{3}} C_{\alpha_{a}}\right]}{L_{4}^{2} C_{\alpha_{a}} C_{\alpha_{4}}+L_{3}^{2} C_{\alpha_{a}} C_{\alpha_{3}}+C_{\alpha_{3}} C_{\alpha_{4}}(d-c)^{2}+m u^{2}\left(c C_{\alpha_{3}}+d C_{\alpha_{4}}-a_{a} C_{\alpha_{a}}\right)}}
\end{gathered}
$$

The desired yaw rate and lateral acceleration can be determined from equation 5 as follows:

Desired yaw rate $\left(r_{d}\right)$ :

$$
\begin{gathered}
r_{d}=\frac{u \delta_{a}\left[L_{4} C_{\alpha_{4}} C_{\alpha_{a}}+L_{3} C_{\alpha_{3}} C_{\alpha_{a}}\right]}{L_{4}^{2} C_{\alpha_{a}} C_{\alpha_{4}}+L_{3}^{2} C_{\alpha_{a}} C_{\alpha_{3}}+C_{\alpha_{3}} C_{\alpha_{4}}(d-c)^{2}+m u^{2}\left(c C_{\alpha_{3}}+d C_{\alpha_{4}}-a_{a} C_{\alpha_{a}}\right)} \\
r_{d}=\frac{u \delta_{a}}{L_{a}+K_{u s} u^{2}}
\end{gathered}
$$

Assuming neutral steer condition for the desired vehicle yaw rate is calculated by setting the understeer coefficient, $K_{u s}=0$. In this case the desired yaw rate, $r_{d}$, can be calculated as follows:

$$
r_{d}=\frac{u \delta_{a}}{L_{a}}
$$


Accordingly the desired lateral acceleration at constant speed, $\mathrm{u}$, becomes as follows:

$$
A_{y_{d}}=u r_{d}
$$

The respective errors in the desired lateral acceleration, $e_{a y}$, and yaw rate, $e_{r}$, can be calculated from the following equations:

$$
\begin{gathered}
e_{a_{y}}=A_{y}-A_{y_{d}} \\
e_{r}=r-r_{d}
\end{gathered}
$$

$A_{y}$ and $r$ are the actual values of the corresponding vehicle states (lateral acceleration and yaw rate, respectively) obtained from actual full vehicle model simulation. The lateral acceleration error $\left(e_{a y}\right)$ and yaw rate error $\left(e_{r}\right)$ are the feedback variables used in the proposed torque vectoring controller design as it will be explained next.

\section{CONTROLLER DESIGN}

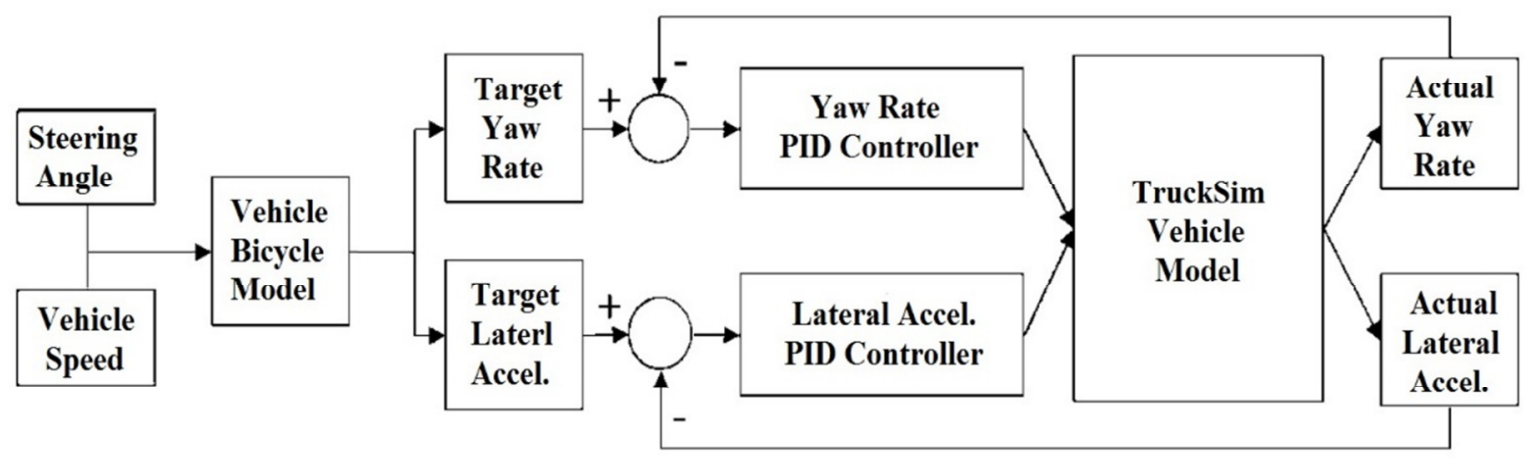

Fig. 3. Schematic of controller interfaced to vehicle model.

\section{Upper Controller}

The objectives of the upper controller are to ensure yaw stability control by commanding desired value of yaw moment and passing it to the lower controller. Inputs to the upper controller are the desired vehicle states defined in control law and the actual states of the vehicle. A PID controller is used as the upper controller to develop the corrective yaw moment which is then passed to the lower controller.

As various standard manoeuvres are executed at constant or nearly constant speed, speed control is introduced in the simulated tests. A PID function is used for the speed controller. The error function, $e_{v}$, is defined as the difference between the actual forward velocity, $v_{x}$, and the desired (simulation) forward velocity of the vehicle, $v_{x d}$. 


$$
e_{v}=V_{x}-V_{x d}
$$

Generally, in all simulations, the total torque $\Delta T_{v}$ is assumed to be equally distributed between all wheels.

\section{Lower Controller}

The lower (level) controller ensures that the corrective yaw moment demanded by the upper controller is converted to a demanded action on a lower level physical vehicle parameter. This parameter, which is generally a braking, driving torque or steering effort, should be properly controlled to achieve the desired corrective yaw moment with the appropriate actuation mechanism. In the case of torque vectoring the developed control strategy, the lower controller is the torque distribution management system that manages the torque distribution between the all wheels to achieve the desired yaw moment.

The final wheel driving torques on the individual wheels can be given by the following equations:

$$
\begin{aligned}
& T_{l 3 \_n e w}=T_{l 3}+\frac{\Delta T_{r}}{2}+\frac{\Delta T_{a y}}{2}+\frac{\Delta T_{v}}{2} \\
& T_{l 4 \_n e w}=T_{l 4}+\frac{\Delta T_{r}}{2}+\frac{\Delta T_{a y}}{2}+\frac{\Delta T_{v}}{2} \\
& T_{r 3 \_n e w}=T_{l 3}-\frac{\Delta T_{r}}{2}-\frac{\Delta T_{a y}}{2}+\frac{\Delta T_{v}}{2} \\
& T_{r 4 \_n e w}=T_{l 4}-\frac{\Delta T_{r}}{2}-\frac{\Delta T_{a y}}{2}+\frac{\Delta T_{v}}{2}
\end{aligned}
$$

Where $\Delta \mathrm{T}$ is the corrective differential torque to be transferred according to the error function for yaw rate, lateral acceleration, and longitudinal vehicle speed as follows:

$$
\begin{gathered}
\Delta T_{r}=K_{p_{-} r} e_{r}+K_{i_{-} r} \int e_{r} d t+K_{d_{-} r} \frac{d}{d t}\left(e_{r}\right) \\
\Delta T_{a y}=K_{p_{-} a y} e_{a y}+K_{i_{-} a y} \int e_{a y} d t+K_{d_{-} a y} \frac{d}{d t}\left(e_{a y}\right) \\
\Delta T_{v}=K_{p_{-} v} e_{v}+K_{i_{-} v} \int e_{v} d t+K_{d_{-} v} \frac{d}{d t}\left(e_{v}\right)
\end{gathered}
$$

\section{MATLAB/Simulink - TruckSim co-Simulator}

Co-simulator that consists of the TruckSim combat vehicle model and MATLAB/Simulink controller was developed to verify the proposed yaw control algorithm, Fig. 4. 


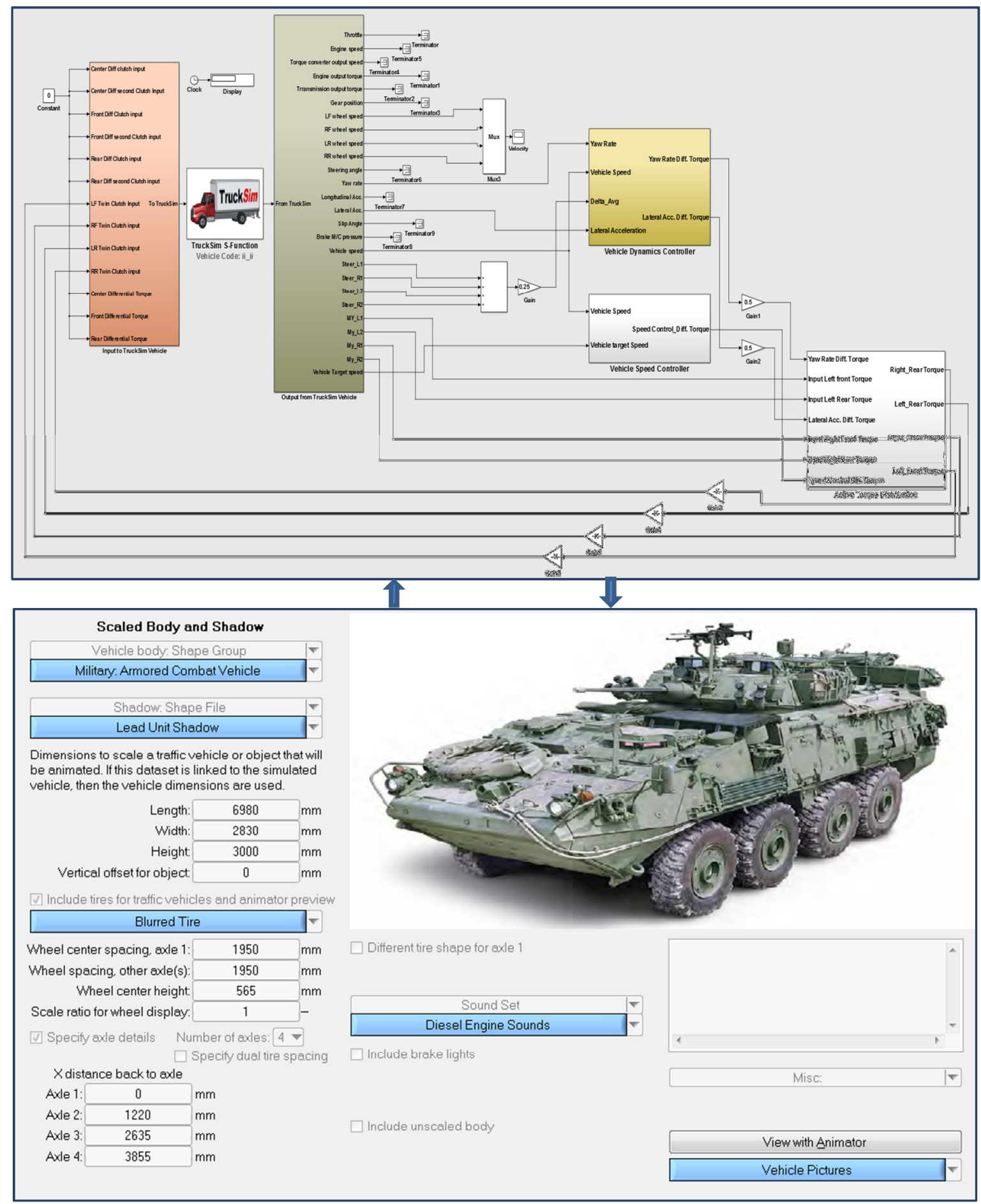

Fig. 4. MATLAB/Simulink - TruckSim co-simulator.

\section{RESULTS AND DISCUSSIONS}

Four simulation manoeuvres have been selected to demonstrate the effectiveness of the proposed design of the torque vectoring control strategy and its effect on $8 \times 4$ combat vehicle performance. The next sections will show the comparison between the vehicle manoeuvrability performance with and without the developed controller. 


\section{Constant Step Slalom (NATO AVTP-1 03-30)}

In this simulation, the initial vehicle speed was $65 \mathrm{~km} / \mathrm{h}$ as shown in Fig. 5. The steering wheel input used in the simulation was obtained from the measurements performed during vehicle model validation as shown in Fig. 6 [15]. The vehicle lateral acceleration and yaw rate are given in Figs. 7 and 8. Figure 9 shows the combat vehicle with and without controller during the simulation.

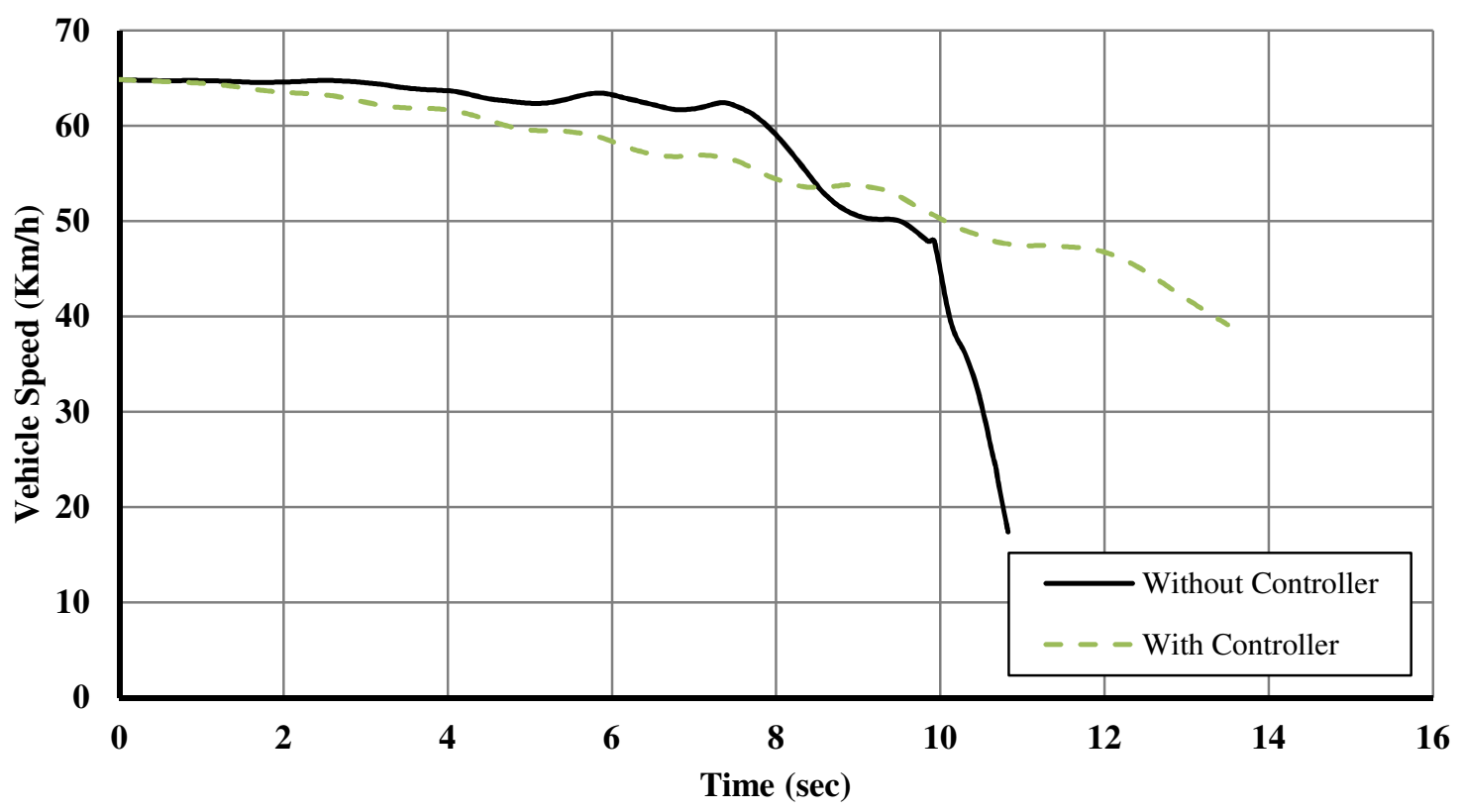

Fig. 5. Vehicle speed time history.

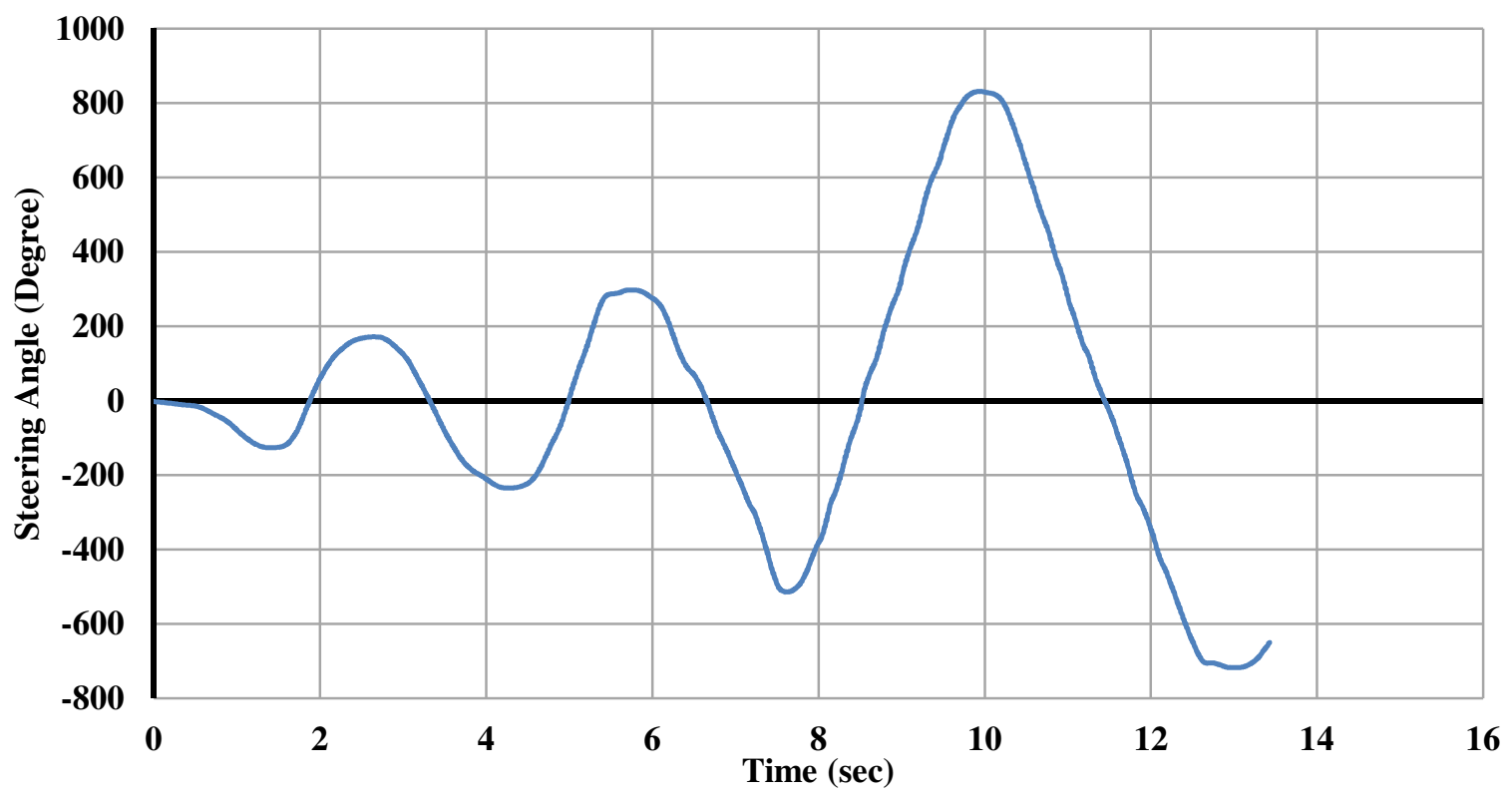

Fig. 6. Vehicle input steering angle time history. 


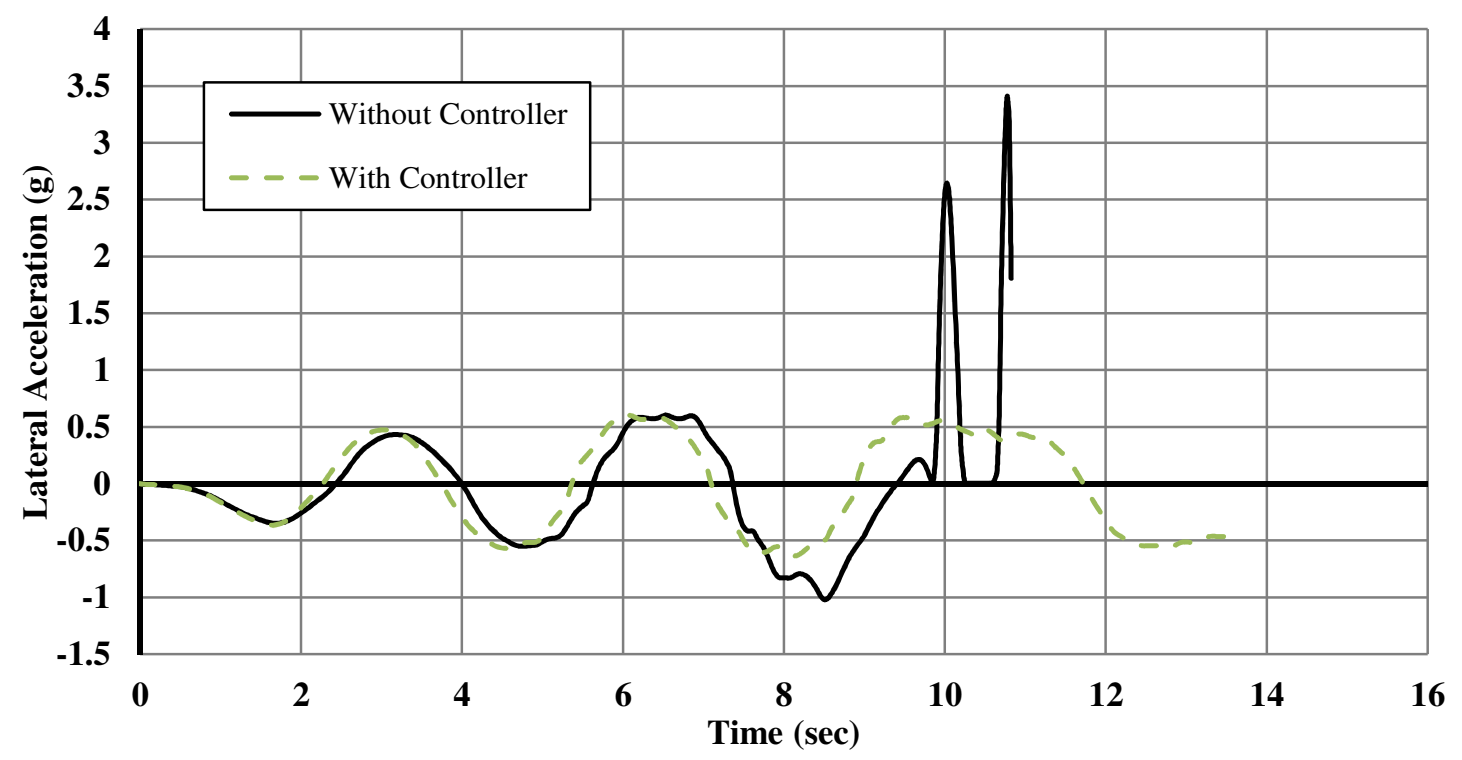

Fig. 7. Vehicle lateral acceleration time history.

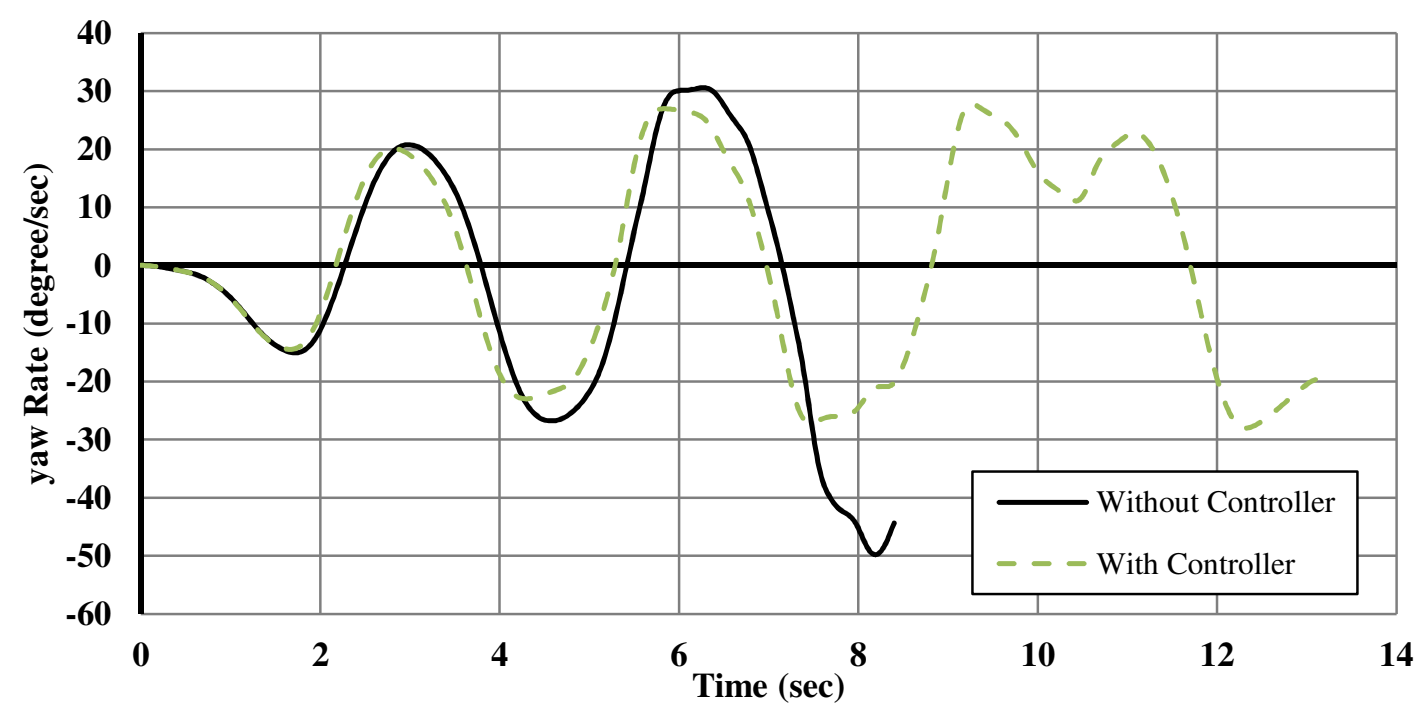

Fig. 8. Vehicle yaw rate time history.

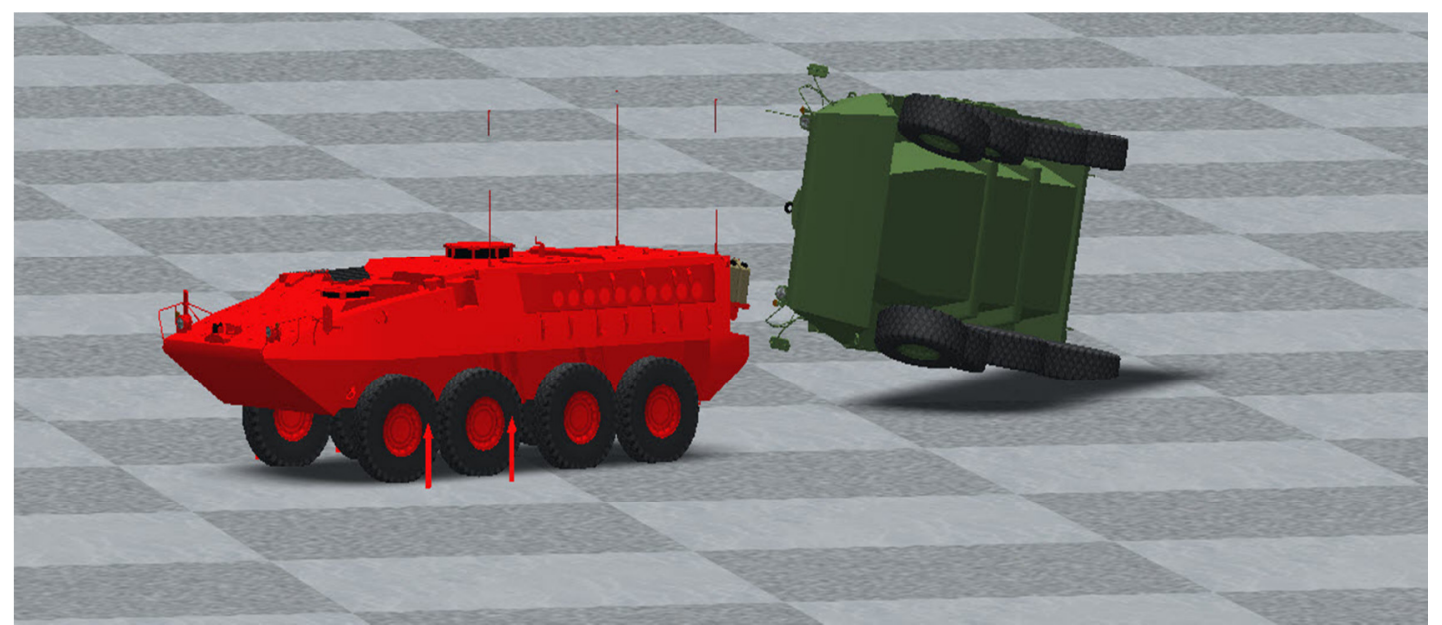

Fig. 9. Vehicle model without controller (Green) and with controller (Red). 
From simulation results, it can be noticed that during the first $5 \mathrm{sec}$ that the proposed controller did not affect the vehicle performance as both lateral acceleration and yaw rate are within the desired values obtained from the bicycle model. And before entering the rollover region, the controller succeeded to reduce both lateral acceleration and yaw rate by generating the required corrective yaw moment with acceptable reduction in vehicle speed to prevent rollover occurrence.

\section{J-Turn (75ft radius)}

In this simulation, the initial vehicle speed was $45 \mathrm{~km} / \mathrm{h}$ as shown in Fig. 10. The steering wheel input used in the simulation was obtained from the measurements as shown in Fig. 11 [15]. The vehicle lateral acceleration and yaw rate are given in Figs. 12 and 13. Figure 14 shows the vehicle with and without controller during the simulation and how the developed controller prevents the vehicle from rollover.

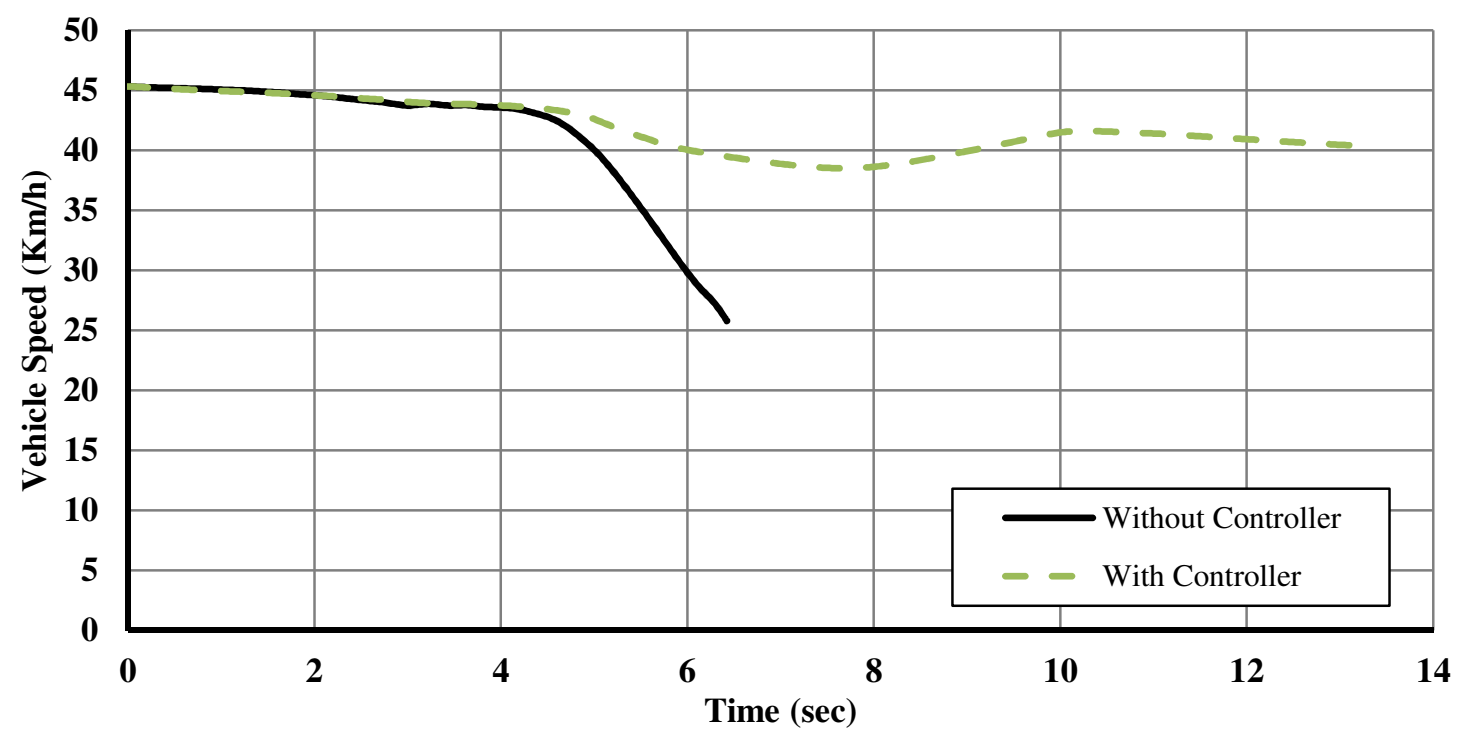

Fig. 10. Vehicle speed time history.

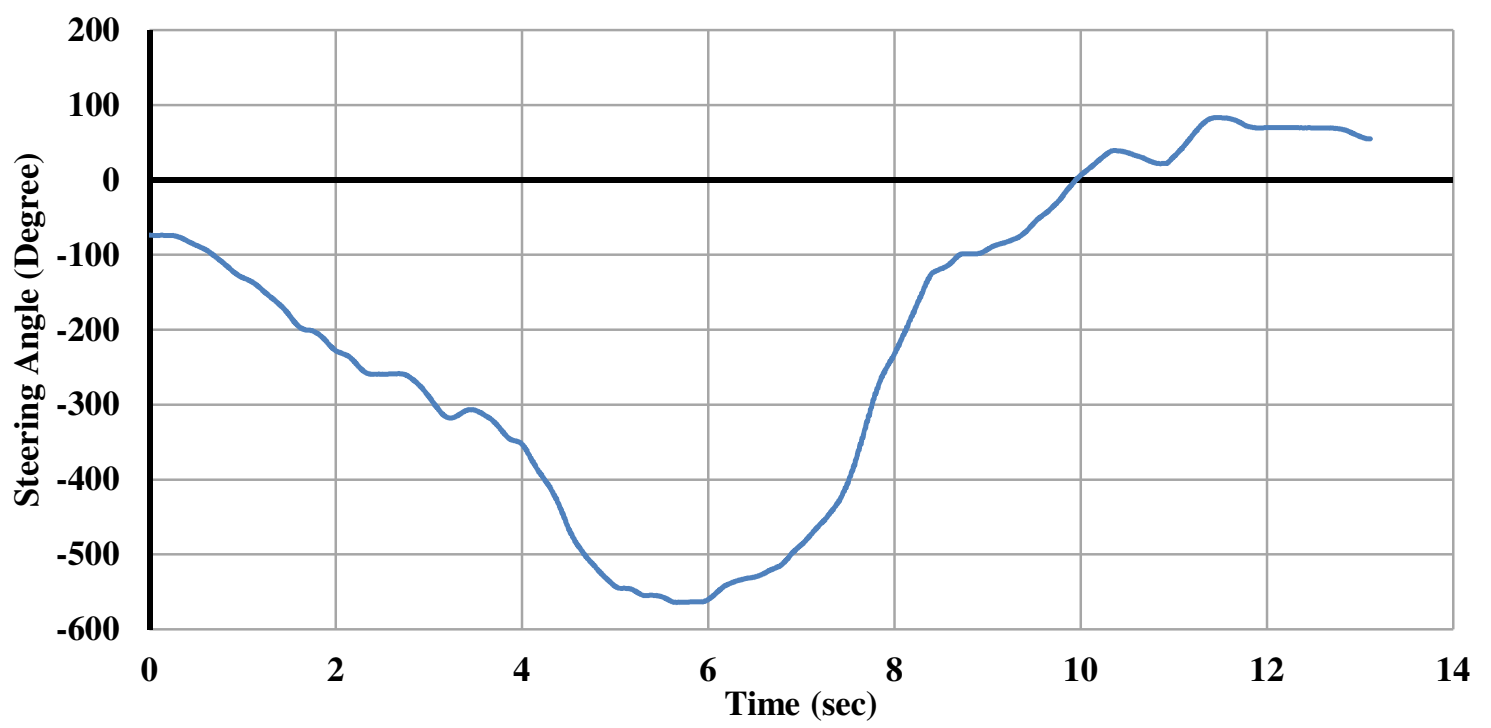

Fig. 11. Vehicle input steering angle time history. 


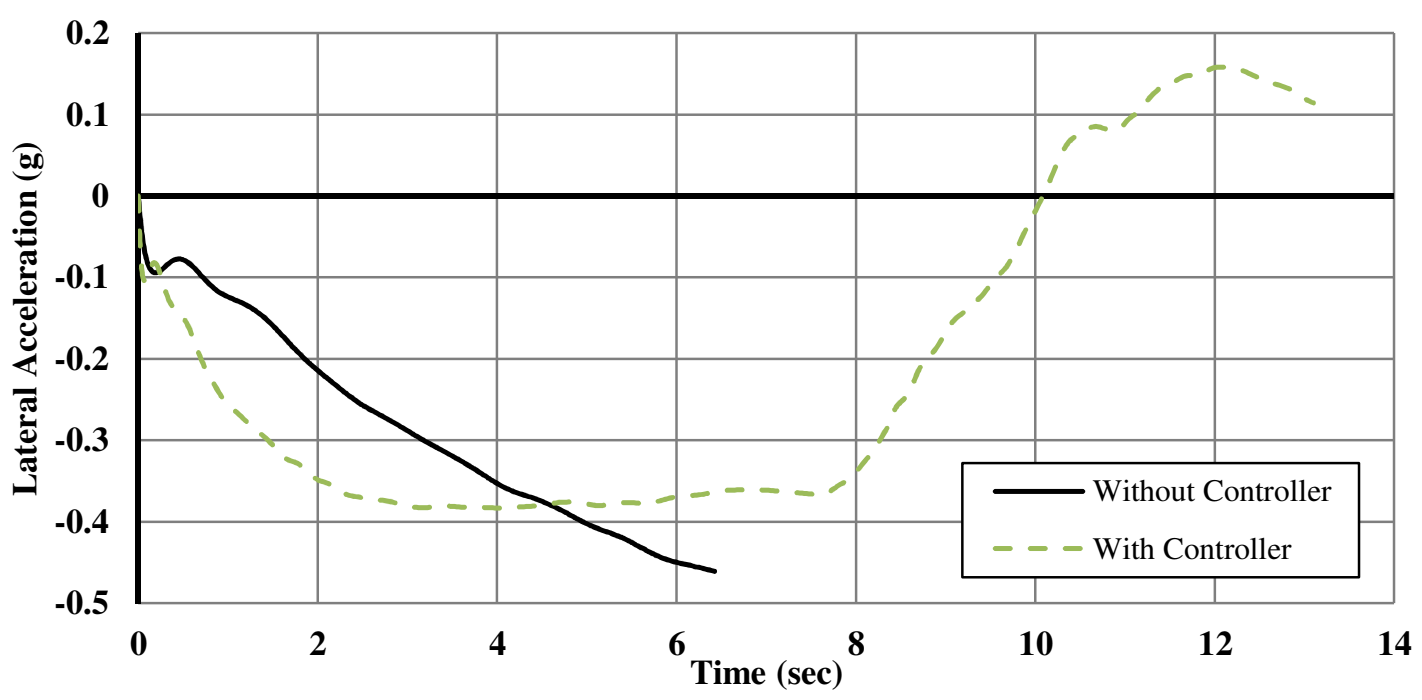

Fig. 12. Vehicle lateral acceleration time history.

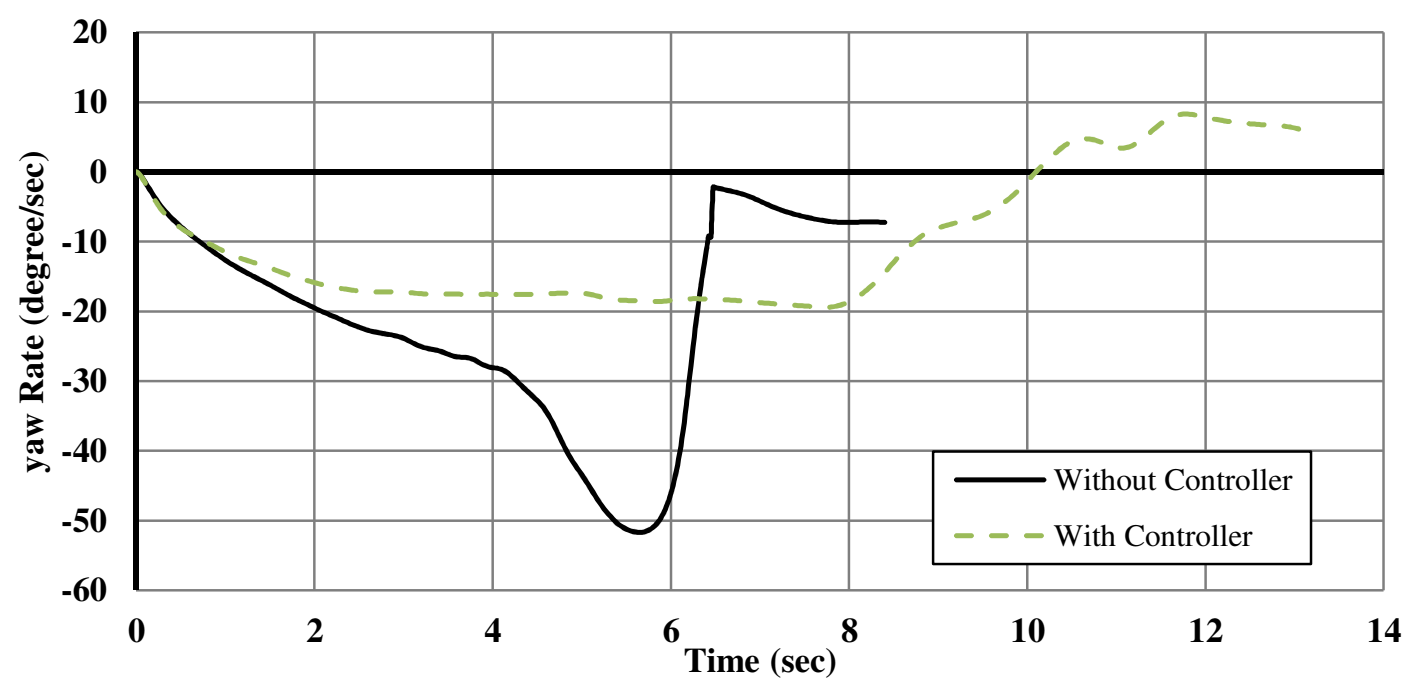

Fig. 13. Vehicle yaw rate time history.

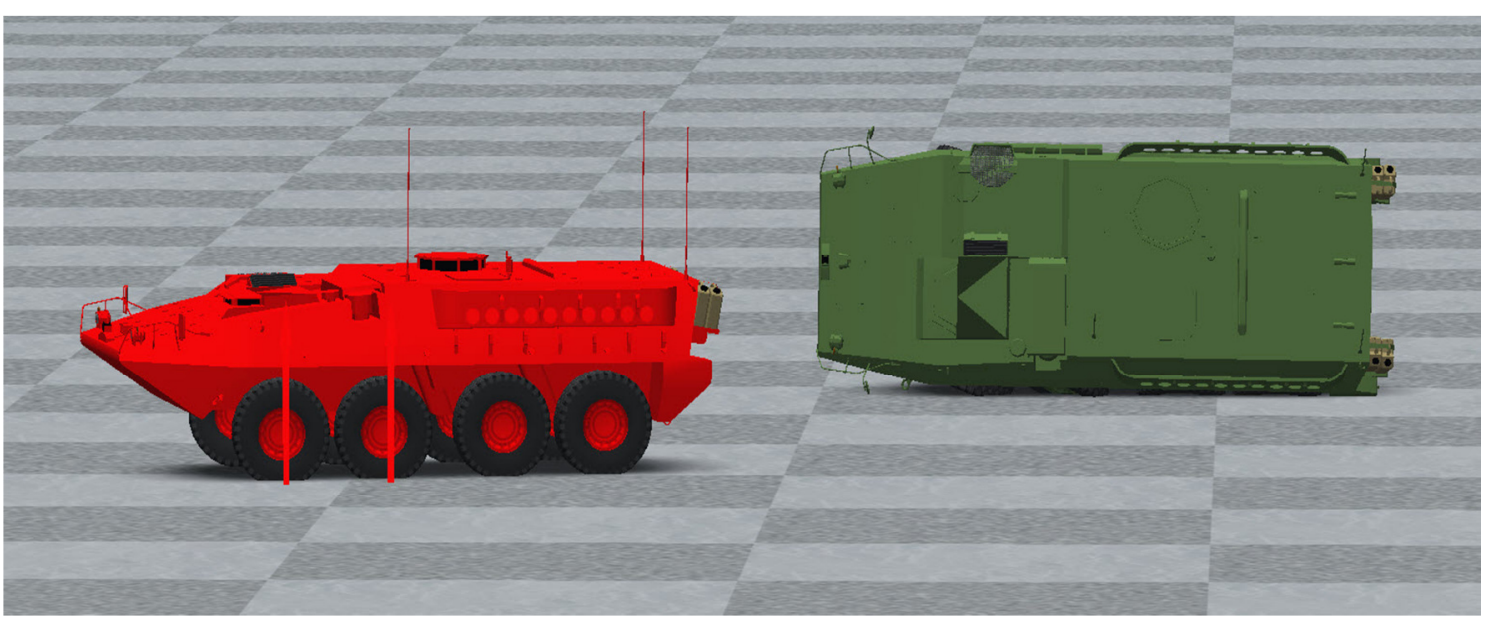

Fig. 14. Vehicle model without controller (Green) and with controller (Red). 
From simulation results, it can be noticed that the proposed control strategy succeeded to largely reduce vehicle yaw rate by generating the required corrective yaw moment which reduced the lateral acceleration while maintaining vehicle speed close to the target value. This action by the controller prevented the vehicle lateral acceleration from reaching the rollover threshold.

\section{Turning Circle (8x4)}

In this simulation, the vehicle speed was maintained at crawling speed as shown in Fig. 15. The steering wheel input used in the simulation was obtained from the measurements as shown in Fig. 16 [15]. The vehicle lateral acceleration and yaw rate are given in Figs. 17 and 18.

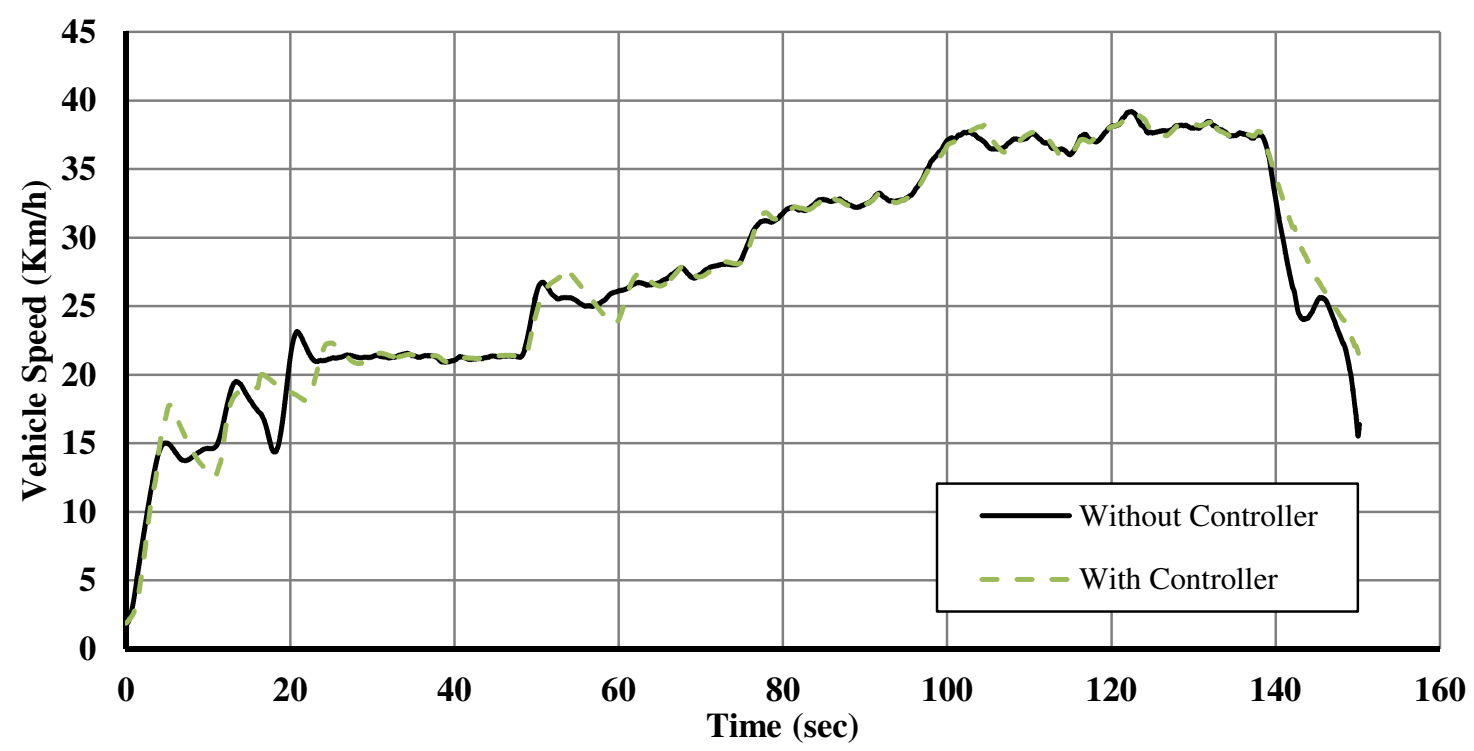

Fig. 15. Vehicle speed time history.

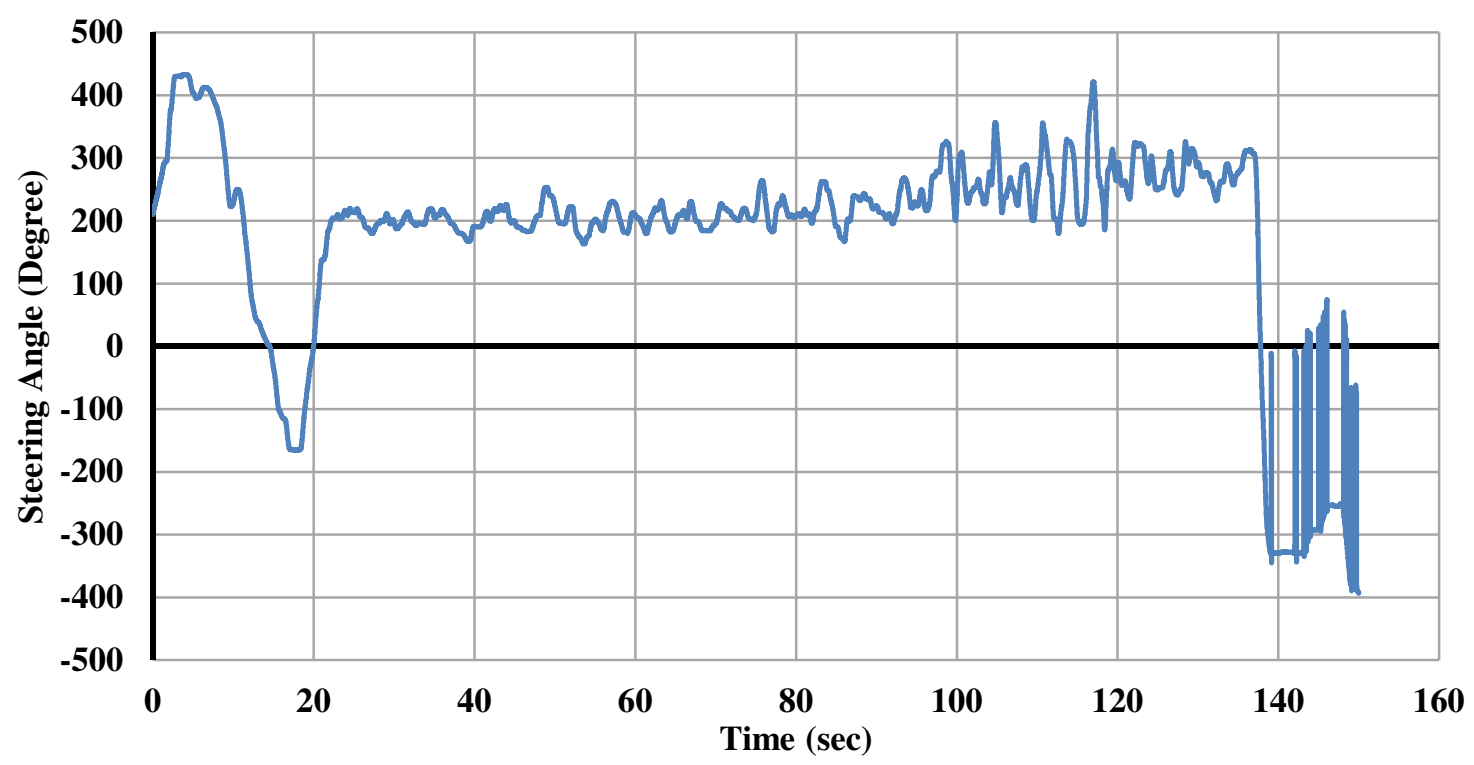

Fig. 16. Vehicle input steering angle time history. 


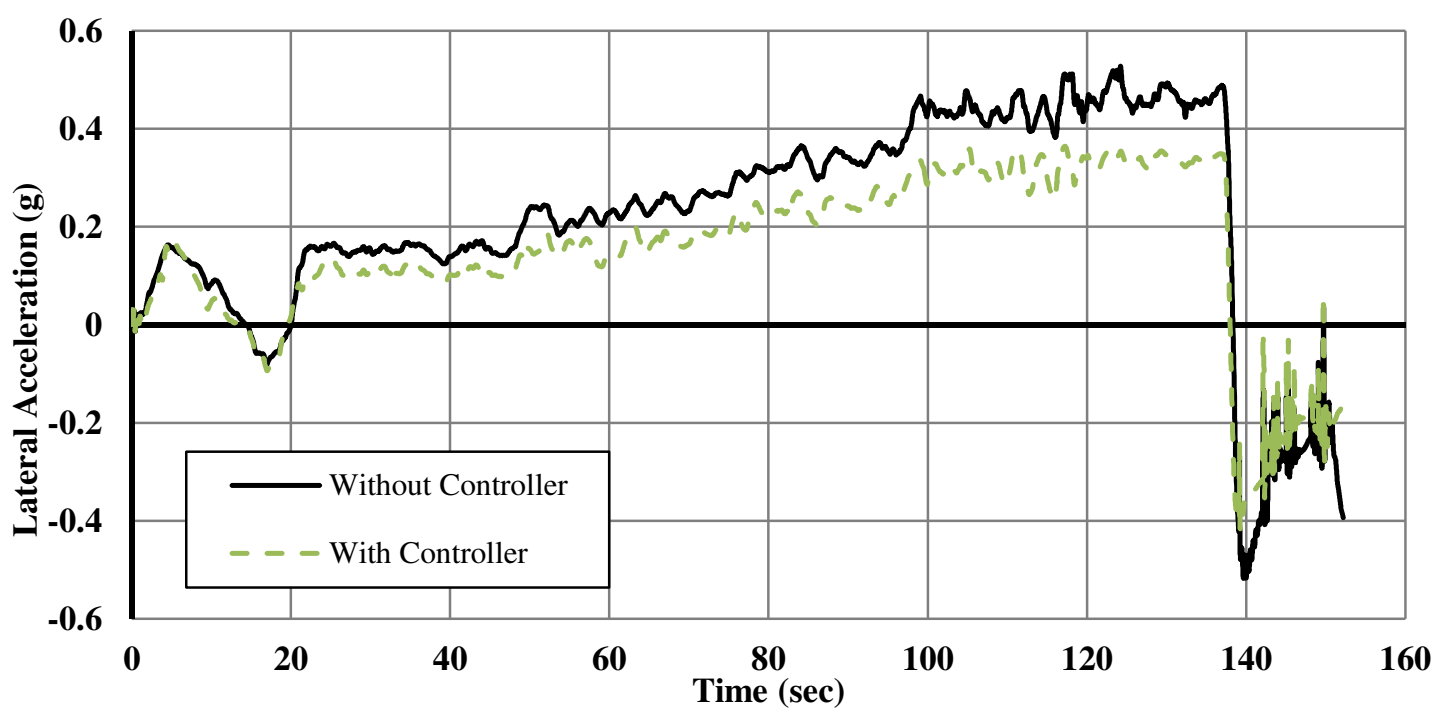

Fig. 17. Vehicle lateral acceleration time history.

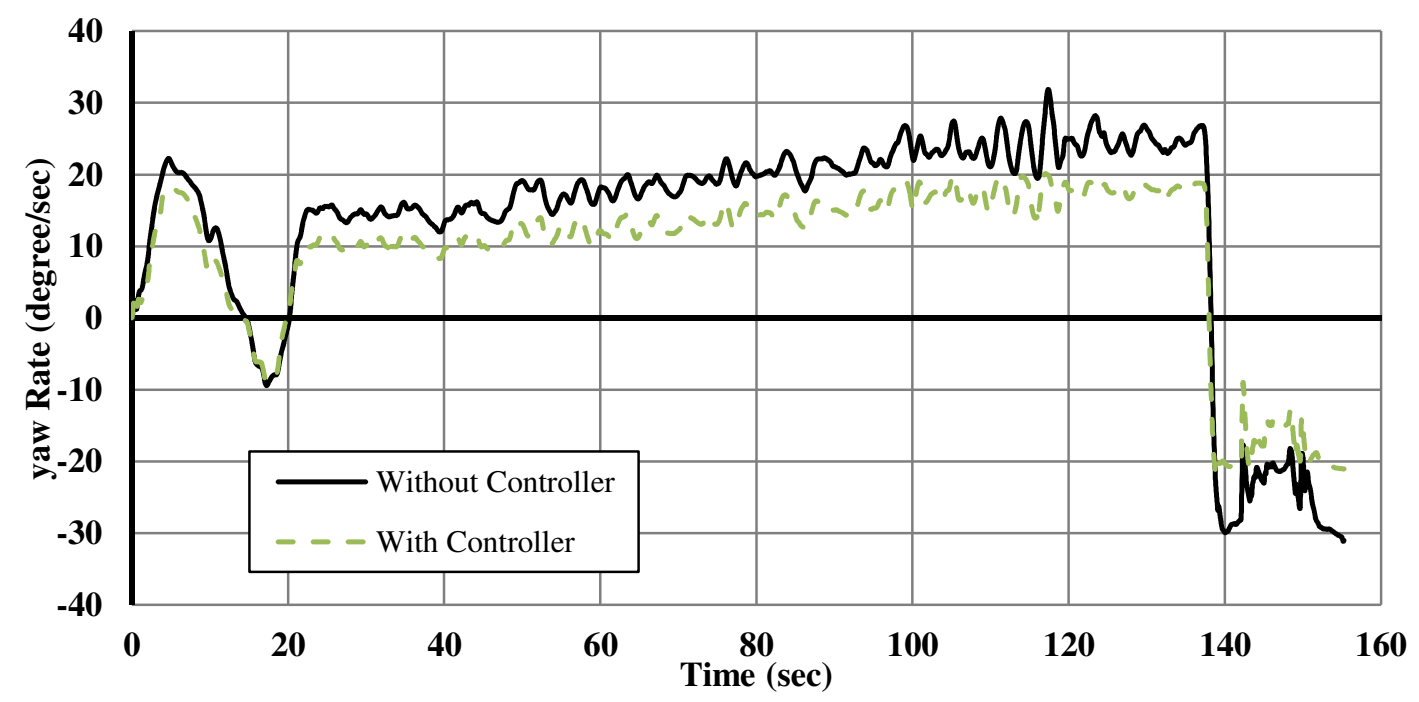

Fig. 18. Vehicle yaw rate time history.

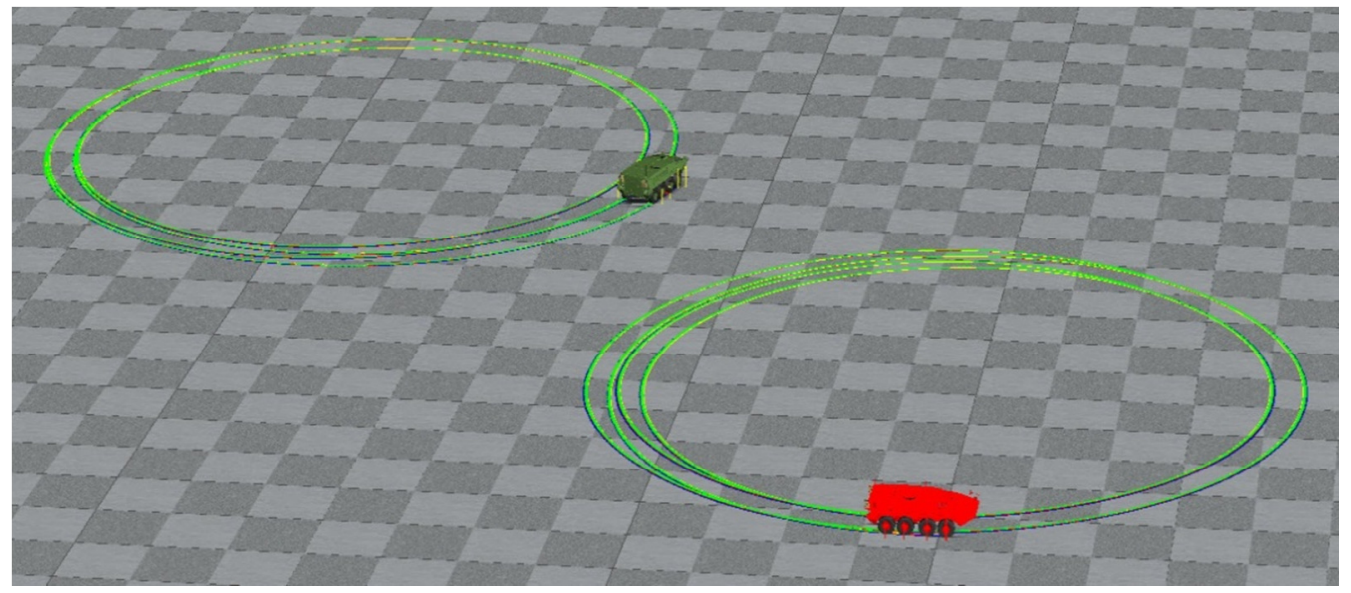

Fig. 19. Vehicle model without controller (Green) and with controller (Red). 
From simulation results, it can be noticed that the proposed control strategy succeeded to reduce both vehicle yaw rate and lateral acceleration at low speeds to the desired yaw rate and lateral acceleration obtained from the vehicle bicycle model.

\section{Constant Radius Simulation}

In this simulation, the vehicle simulation course of $100 \mathrm{ft}$. radius, Fig. 20, was performed at constant speed. This simulation is used to verify the effectiveness of the proposed control strategy and its effect on vehicle directional stability.

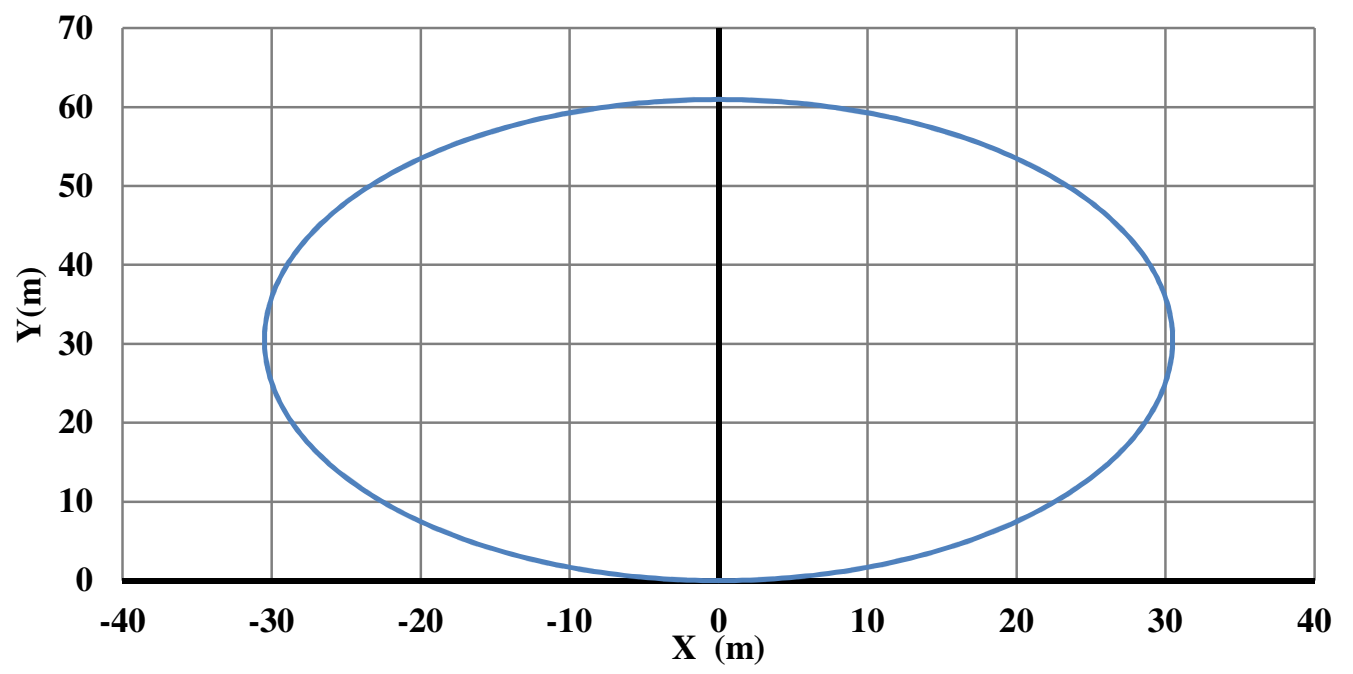

Fig. 20. Vehicle course for constant radius simulation (100 ft. radius).

The vehicle speed was maintained approximately at $45 \mathrm{~km} / \mathrm{h}$ as shown in Fig. 21 . The vehicle lateral acceleration and yaw rate are given in Figs. 22 and 23. Figure 24 shows combat vehicle trajectory with and without controller during the simulation.

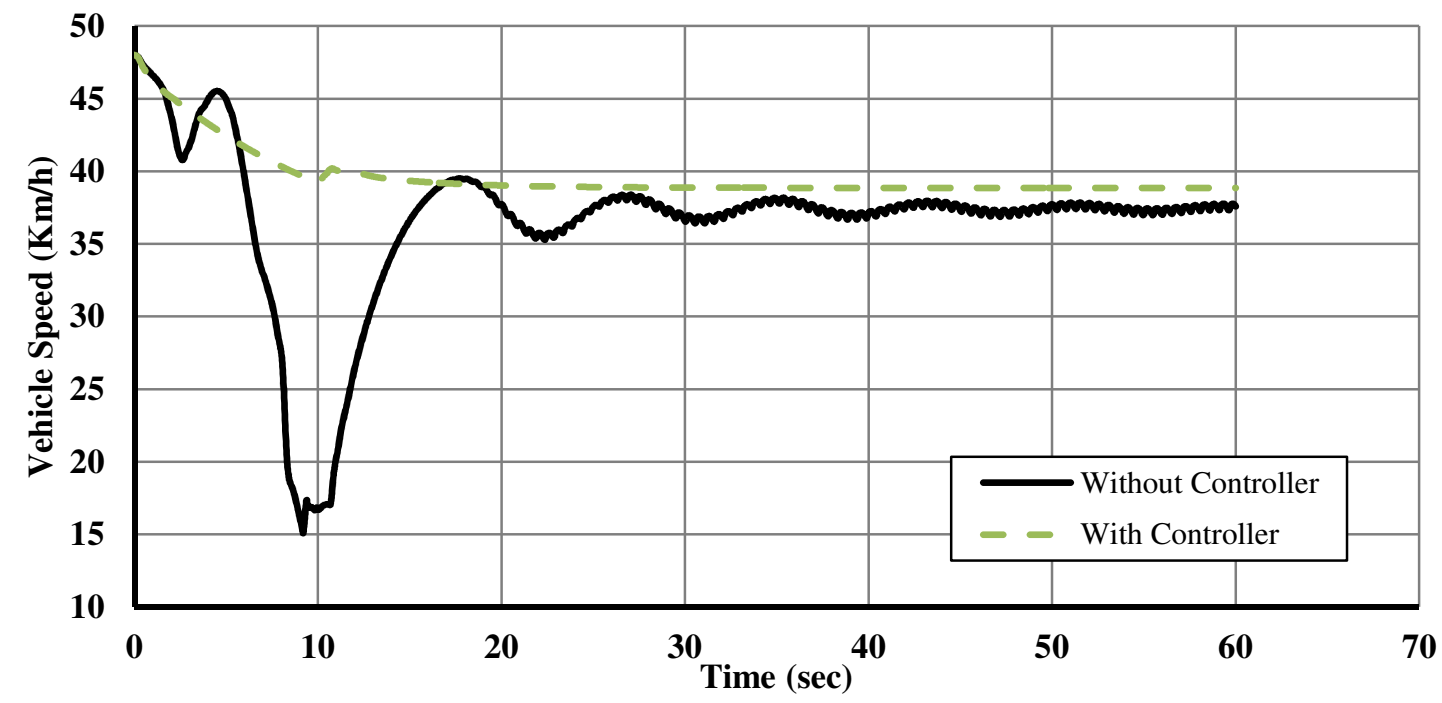

Fig. 21. Vehicle speed time history. 


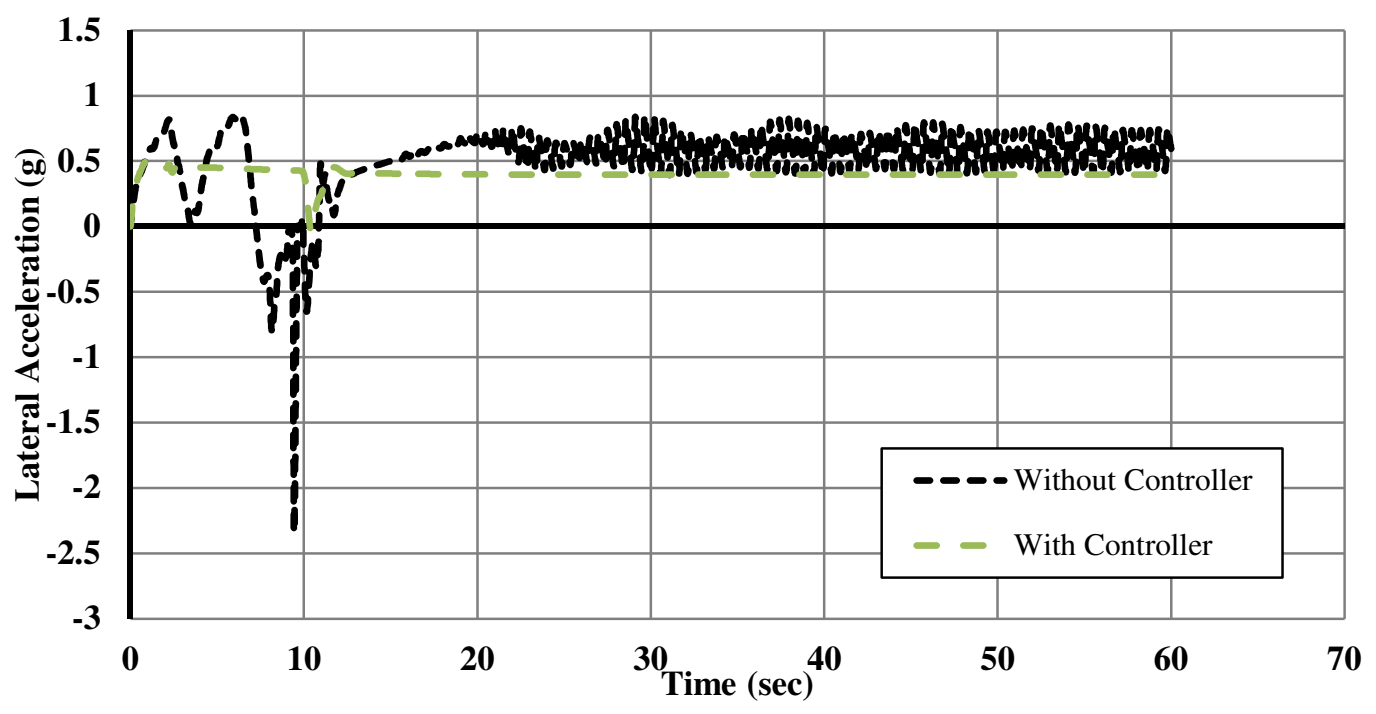

Fig. 22. Vehicle lateral acceleration time history.

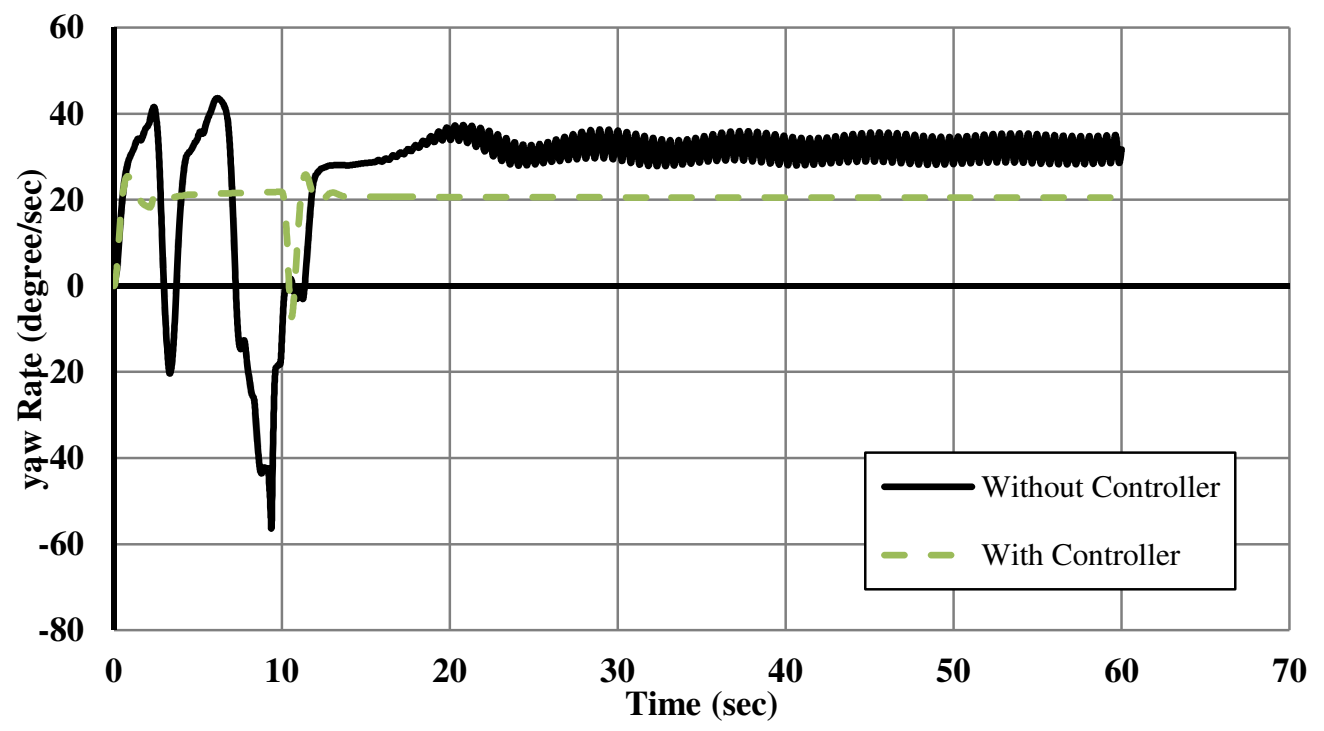

Fig. 23. Vehicle yaw rate time history.

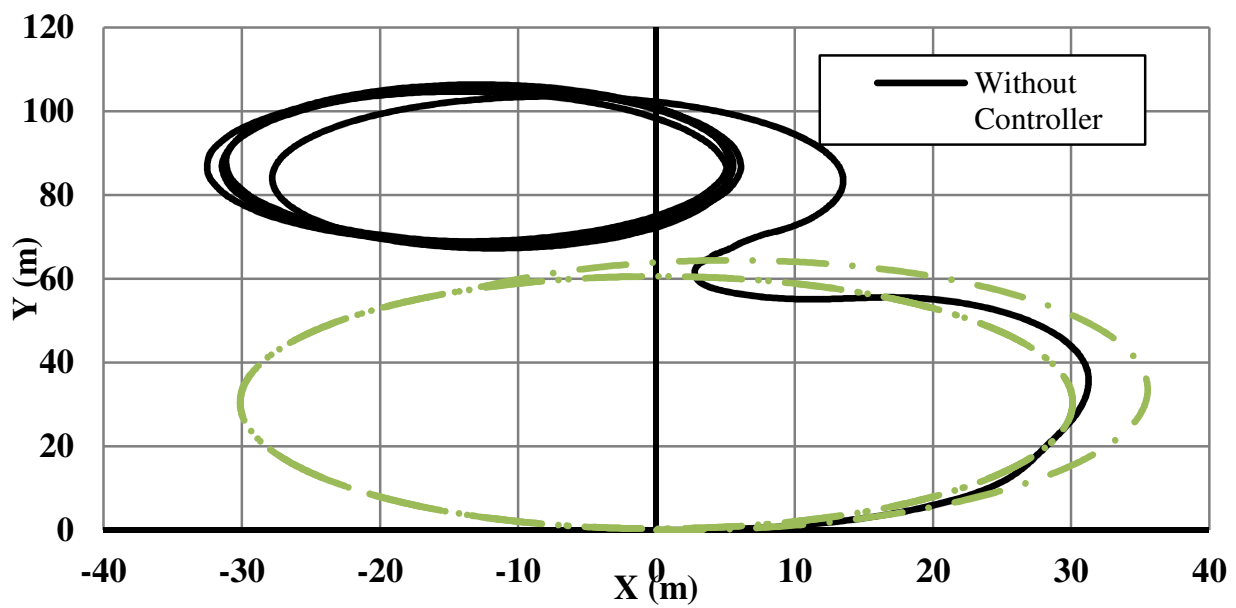

Fig. 24. Vehicle trajectory. 
This simulation has been performed at different speeds starting from $10 \mathrm{~km} / \mathrm{h}$ with increment of $5 \mathrm{~km} / \mathrm{h}$ until the simulation path could not be completed at $45 \mathrm{~km} / \mathrm{h}$.

From simulation results, it can be noticed that the proposed control strategy succeeded to reduce both vehicle yaw rate and lateral acceleration and preventing partial rollover at $9 \mathrm{sec}$. which affect vehicle capability of completing the objective simulation course.

\section{CONCLUSIONS}

This paper presents the development and simulation of PID controllers to enhance the directional stability and mobility of a multi-wheeled combat vehicle.

Comparison between vehicle directional performance with and without the proposed control strategy was performed using different standard tests, namely Constant step slalom, J-turn, turning circle and Constant radius simulation.

From these tests, it can be concluded that;

- In case of Constant Step Slalom (NATO AVTP-1 03-30) and J-Turn (75ft radius), the proposed controller enhanced both yaw rate and lateral acceleration and succeeded in preventing rollover in both testing maneuvers.

- In case of turning circle $(8 \times 4)$ test, the proposed controller enhanced both yaw rate and lateral acceleration.

- In case of Constant radius simulation, the proposed controller enhanced both lateral acceleration during all the performed tests at 35 and $40 \mathrm{~km} / \mathrm{h}$. In addition, the performed test at $45 \mathrm{~km} / \mathrm{h}$ helped the vehicle with controller to remain in the desired path.

From the aforementioned conclusions, more research effort is required to develop the controller for $8 \times 8$ vehicle powertrain configuration on rigid road. In addition, developing the proposed control strategy for off-road operations (soft soil) with implementing tire slip controller.

\section{ACKNOWLEDGMENT}

The authors wish to express their gratitude to the Egyptian Military Attaché's Office in Washington DC for the financial support extended to this research project. The authors would like to extend special thanks to all Automotive Department members at Military Technical College for their technical support.

The authors would like also to express their appreciation to GDLS-Canada for their continuous technical help during the course of this study. 


\section{REFERENCES}

[1] Kaoru Sawasea and Yoshiaki Sanob, "Application of Active Yaw Control to Vehicle Dynamics by Utilizing Driving/Braking Force ", Society of Automotive Engineers of Japan Symposium No. 9702, 9730894, (1999).

[2] Mohan, "Torque vectoring systems, Architecture, stability performance and efficiency considerations", 6th All-Wheel Drive Congress Graz, (2005).

[3] Weals et al., "SUV demonstration of a torque vectoring driveline and new concepts for practical actuation technologies", JSAE annual congress, No. 3805 194, (2005).

[4] Kaoru SAWASE, Yuichi USHIRODA and Takami MIURA, Mitsubishi Motors, Technical Review, No.18, (2006).

[5] Piyabongkarn, D., Grogg, J., Yuan, Q., Lew, J. et al., "Dynamic Modeling of Torque-Biasing Devices for Vehicle Yaw Control," SAE Technical Paper 200601-1963, (2006).

[6] S. Zheng et al., "Controller design for vehicle stability enhancement", Control Engineering Practice 14 (2006) 1413-1421

[7] Kaoru SAWASE and Yuichi USHIRODA, Mitsubishi Motors, Technical Review, No.20, (2008).

[8] Gerd Kaiser, Qin Liu, Christian Hoffmann, Matthias Korte and Herbert Werner, "Torque vectoring for an electric vehicle using an LPV drive controller and a torque and slip limiter", 51st IEEE Conference on Decision and Control December 10-13,Maui, Hawaii, USA, (2012).

[9] M. M. Al EmranHasan, M. Motamed Ektesabi, A. Kapoor, "An Investigation into Differential Torque Based Strategies for Electronic Stability Control in an InWheel Electric Vehicle" International Journal of Engineering and Innovative Technology (IJEIT) Volume 2, Issue 7, (2013).

[10] Russell P. Osborn and Taehyun Shim, "Independent control of all-wheel drive torque distribution", International Journal of Vehicle Mechanics and Mobility, 44:7, 529-546, (2006).

[11] Jackson, and D. Crolla, "Improving Performance of a $6 \times 6$ Off-road Vehicle through Individual Wheel Control ", SAE Paper Series, No. 2002-01-0968, (2002).

[12] H. Ragheb, M. El-Gindy, H.A. Kishawy, Multi-Wheeled Combat Vehicle Maneuverability on Rigid and Soft Terrain, 15th International Conference on Aerospace Sciences and Aviation Technology, ASAT-15, Paper ID: 165-ST, Military Technical College, May 28-30, Cairo, Egypt, (2013).

[13] Wongun Kim, Kyongsu Yi, and Jongseok Lee, "Drive control algorithm for an independent 8 in-wheel motor drive vehicle", Journal of Mechanical Science and Technology, Vol.25 (6), pp. 1573-1581, (2011)

[14] Ragheb, H., El-Gindy, M. and Kishawy, H., "Development of a Combat Vehicle FEA Tire Model for Off-Road Applications", SAE 2013 World Congress \& Exhibition, April 16-18, Detroit, Michigan, USA, (2013).

[15] Moustafa El-Gindy and Hossam Ragheb, "Torque control strategy for off-road vehicle (off-road vehicle mobility)", Technical Report No. 1, Submitted to GDLS-Canada, London, Ontario, Canada, November 22, 2013.

[16] A.Ghoneim, Youssef, et al.," Integrated chassis control system to enhance vehicle stability", International Journal of Vehicle Design, Vol. 23, pp. 124-144, (2000). 